\title{
A emêrgencia de cosmovisões relacionais
}

\author{
Marilia Veríssimo Veronese \\ Maria Luísa Carvalho*
}

\section{Introdução}

Durante o processo de revisão teórica para nossas respectivas teses de doutorado (Veronese, 2004; Carvalho, 2005), ambas versando sobre alternativas solidárias de produção econômica, nos deparamos com três conceitos: cultura da partilha (Araújo, 1998, 2002; Lubich, 2002), paradigma da dádiva (Mauss, 2001; Caillé, 2000; Godbout, 1999) e comunitarismo solidário (Guareschi, 2004). Partindo de uma abordagem psicossocial, atentamos para eventuais similaridades entre eles, oriundos de áreas disciplinares distintas como a sociologia, antropologia e psicologia social.

* Marilia Veríssimo Veronese é doutora em Psicologia pela Pucrs, docente e pesquisadora do PPG em Ciências Sociais da Unisinos. Publicou, entre outros, Análise de um empreendimento de economia solidária sob a ótica da sociologia das ausências e das emergências (Ciências Sociais Unisinos, 2005) e Possibilidades solidárias e emancipatórias no trabalho (com Pedrinho A. Guareschi, Psicologia \& Sociedade, 2005). Página: www.ecosol.org.br. E-mail: mariliav@unisinos.br.

Maria Luísa Carvalho é doutoranda em psicologia pela Pucrs, docente da Ulbra. Publicou, entre outros, Gerenciamento de impressão e entrevista de seleção (com C. Grisci, Psicologia Ciência e Profissão, 2004) e Capitalismo flexivel, subjetividade e resistência (In: Psicologia em contexto: Edipucrs, 2003). E-mail: mlcarvalho@pop.com.br.

\begin{tabular}{|c|c|c|c|c|c|}
\hline Civitas & Porto Alegre & v. 6 & n. 2 & jul.-dez. 2006 & p. 169-194 \\
\hline
\end{tabular}


Estamos trabalhando com a idéia de que essas realidades distintas sugerem a emergência de uma cosmovisão que se apresentaria como uma tentativa de superação de duas cosmovisões típicas das sociedades ocidentais modernas, o individualismo e o totalitarismo. Constituem, assim, o que estamos denominando por cosmovisões relacionais, uma vez que caracterizam-se por apresentarem o ser humano como um sujeito-em-relação, propondo um modelo de sociedade pautado na solidariedade e na cooperação.

Optamos por utilizar o termo cosmovisão, no lugar de paradigma, por considerá-lo mais preciso. Ou seja, o termo paradigma costuma ser empregado de forma genérica para designar um modelo, onde haja um consenso relativo em dada comunidade científica, proporcionando um enquadramento para os resultados da pesquisa científica (Khun, 1987). Já por cosmovisão indicase, conforme Guareschi (2004), uma visão de mundo ou cosmovisão, ao mesmo tempo social e individual, que traduz a forma como o compreendemos o mundo e nos relacionamos com ele. Inclui elementos como o modelo de sociedade, a concepção de ser humano, os valores, os tipos de relação estabelecidos com os demais, dentre outros. O interesse e a pertinência da discussão proposta nesse texto vêm do fato de que uma cosmovisão não é algo abstrato, mas traduz-se em práticas, permeando a teoria e a ação social.

Dessa forma, pretendemos inicialmente resgatar as cosmovisões hegemônicas e opostas, o Individualismo e o Totalitarismo, apontando suas características e limitações. Em seguida, apresentaremos as cosmovisões emergentes: o comunitarismo solidário, o paradigma da dádiva e a cultura da partilha, buscando ressaltar as semelhanças e diferenças entre elas, analisando-as criticamente, bem como alguns exemplos de ações que eventualmente concretizem, materializem os elementos presentes em cada uma.

Faz-se necessário lembrar que nenhuma cosmovisão apresenta-se de forma plena, livre de contradições, além de que, historicamente, cosmovisões relacionais foram constituídas em diferentes momentos e lugares (mutualidades, socialismo utópico etc). O que fazemos, no texto, é uma análise de cada conceito separadamente, para fins de entendimento e clareza na apresentação. 


\section{A cosmovisão individualista}

O termo individualismo é associado aos conceitos de utilitarismo, contratualismo, instrumentalismo e liberalismo, tendo ganhado força a partir da ascensão do capitalismo como modo de produção hegemônico. Embora tal manifestação, em termos de idéias e de práticas sociais, remonte à Grécia antiga, não abordaremos exaustivamente seu histórico por não ser nosso objetivo nesse texto.

Eticamente, essa cosmovisão coloca a liberdade individual e o direito de ação dos indivíduos acima da necessidade coletiva. Em termos de leitura da sociedade, esta só pode ser explicada na perspectiva das ações individuais (individualismo metodológico nas ciências sociais). Indivíduos racionais e livres é que produzem a sociedade; Tomás de Aquino, ao elaborar a idéia do indivíduo como a mais perfeita criação divina, imprime no pensamento cristão essa marca, que seria aprofundada na reforma protestante. Hobbes concebe o ser humano como autônomo e único; essa concepção é acompanhada da ascensão do egoísmo e do amor-próprio na sociedade inglesa de sua época, até então vistos como pejorativos (Wieland, 1997).

O liberalismo, na esteira do iluminismo, está centrado no indivíduo e no compromisso com a liberdade individual. Para Guareschi (2004), essa cosmovisão apresenta uma perspectiva filosófica na qual o ser humano é um indivíduo - indivisum in si et quolibet alio - ou seja, uno, indivisível e sem relação com o outro. No campo da economia, traduz-se como homo economicus, um ser auto-suficiente, egoísta, separado dos demais, que busca unicamente maximizar racionalmente a satisfação de seu próprio interesse. Concebida sob a égide do paradigma da escassez, a economia, modernamente, será focada na acumulação, não na distribuição. O Individualismo acentua e reforça as diferenças, não no sentido de valorizar a singularidade e a pluralidade, mas para justificar e naturalizar as desigualdades e gerar a divisão. $\mathrm{O}$ outro é visto com indiferença ou desconfiança, um potencial competidor a ser subjugado.

A visão apresentada por esse autor, entretanto, pode ser relativizada. Segundo Pies (1997, p. 359):

Os competidores - cidadãos - têm interesse numa ordem geral que funcione e canalize de tal modo as ações individuais de concorrência, que os resultados do 
jogo da competição sejam favoráveis a todos [...]. Uma sociedade liberal pode simultaneamente empregar a cooperação e a competição, embora em níveis diversos.

Contemporaneamente, sabe-se que, em termos econômicos, as cadeias produtivas incluem elementos de cooperação e competição, dependendo do contexto, segmento, negócio etc. Ainda assim, acreditamos que se pode manter a crítica fundamental do modelo de sociedade proposto pelo individualismo, qual seja, o capitalismo liberal, segundo o qual o sistema de produção e de circulação de bens e serviços é regido pelo interesse, pela racionalidade e pela utilidade. Na medida em que se otimiza o interesse individual, os membros de uma sociedade produzem o máximo de bem-estar coletivo, uma vez que a sociedade é tida como a soma dos indivíduos (Godbout, 1999; Guareschi, 2004).

Os valores dessa cosmovisão emergem de pressupostos importantes da modernidade ocidental, já que avalizaram a autonomia individual frente a coletivos potencialmente opressores; na sua origem, foram emancipatórios porque permitiram o empoderamento do sujeito individual diante da tradição. Contudo, ao longo dos últimos dois séculos, parece claro que produzem relações caracterizadas pela instrumentalidade, pelo egocentrismo e pela competição (Bruni, 2002; Guareschi, 2004). O outro é um meio para que eu alcance meus objetivos, e deve ser combatido caso me atrapalhe. As relações sociais são dominadas por questões mercantis, sendo a sociedade considerada como um grande mercado. Nesse cenário, o equilíbrio social é buscado através de ajustamentos entre os interesses individuais, regulados através de contratos que regem as relações cotidianas (Nicolas, 2002).

A concepção utilitarista está enraizada, por exemplo, nas tradições de pensamento que concebem a exigência básica da moral como o aumento da soma dos proveitos individuais; a maximização da utilidade visada seria eticamente positiva, uma vez que todos se beneficiariam dessas ações (Kley, 1997). Entretanto, as evidências empíricas mostram, sem engano, que nas sociedades ocidentais contemporâneas, onde prevalece tal concepção, a desigualdade social aumenta e o fosso entre pobres e ricos só cresce (Santos, 2001; Singer, 2002; Cattani, 2002; Carvalho Neto, 2001). Da legitimação do $e u$, passou-se à apologia do eu; Farr (1998) argumenta que no ocidente o 
individualismo seria a última das representações coletivas, uma representação do eu que o concebe livre e independente da sociedade.

O Individualismo "liberta" o sujeito de relações sociais indesejáveis, inumeráveis em uma sociedade pluralista; assim, pode-se facilmente sair de uma relação e buscar outra. A fragilidade dos laços humanos na contemporaneidade foi discutida com primor por Bauman (2004), tanto na perspectiva das relações sociais no âmbito da cidadania e da esfera pública, quanto nas relações amorosas de cunho erótico, apontando suas conseqüências não apenas para as relações primárias, mas na própria vida em sociedade, uma vez que corrói o vínculo social e gera indiferença ao sofrimento alheio. Embora a psicanálise advirta que o vínculo erótico é frágil por natureza (Khel, 2000), as instituições sociais que dele decorrem, como a família, são também impactadas pelo tipo de cosmovisão hegemônica em uma sociedade.

No Individualismo, cada relação é pontual, não envolvendo um sistema de obrigações. Porém, se por um lado o indivíduo encontra-se liberto dos vínculos sociais, por outro, ele se torna dependente de seus bens, que acabam tendo um valor supremo em si, não visando mais atender as suas preferências e necessidades (Godbout, 1999; Bauman, 2004).

Sennet (1999) é outro autor que discute como o capitalismo flexível, expressão do neoliberalismo, "corrói o caráter", rompendo os vínculos sociais e promovendo a extinção de valores como fidelidade e lealdade, considerados valores a longo prazo, mas descartáveis num mundo cujo lema é o imediatismo e a criação fugaz de novas "necessidades".

Parece-nos ainda interessante a análise de Bauman (2001), no que se refere ao mundo do trabalho, ao ressaltar o desengajamento unilateral do capital em relação ao trabalho. Nos tempos modernos de Chaplin, capital e trabalho, na sua relação conflituosa e intensa, estavam "amarrados" um ao outro por laços de interdependência. O capital precisava do trabalhador, ou o lucro era impossível de obter-se. Na versão do capitalismo liqüefeito, flexível e desregulado, o trabalhador tornou-se "peso morto", muitas vezes nem mesmo necessário, e o capital retira-se, aliviado, da relação de reciprocidade (Veronese, 2004). A lógica do capital é, no fundo, simples: produzir acumulação mediante exploração. 
O Individualismo está por trás da construção de uma ciência igualmente individualista, na qual o agente individual, pode ser analisado independentemente das suas relações com o outro. Foi na ciência econômica que a afirmação do valor do indivíduo encontrou maior expressão, uma vez que a economia capitalista parte do pressuposto de que os indivíduos não estão ligados uns aos outros por nexos indivisíveis, antes de iniciar uma troca (Bruni, 2002).

Na psicologia, tal cosmovisão esteve presente nas origens da mesma enquanto ciência, contribuindo para a legitimação de uma visão de ser humano a-histórico, isolado dos demais, com uma personalidade inata, a ser "descoberta" e "avaliada" pela psicometria. O social é negado ou visto como algo externo e estranho ao $e u$, que dificulta o pleno e livre desenvolvimento do "mundo interior". Gera-se o chamado "psicologismo", sendo que tudo é explicado a partir do indivíduo. A herança cartesiana que coloca o cogito individual como medida de veracidade e racionalidade, passando o social a ser considerado campo de produção de irracionalidades é carregada pela psicologia (hegemônica) como ciência até os dias de hoje, em outros termos obviamente. Essa tendência hegemoniza-se com a ascensão do capitalismo, da moral calvinista e do ethos, do zeitgest que se produziu então, favorável ao individualismo, penitência pelo trabalho e legitimação religiosa do acúmulo de lucro.

O Behaviorismo, a título de exemplo, ignora - ou pelo menos assim o fez, nas suas primeiras formulações, - o social enquanto cultura, considerando como estímulos apenas as influências que atuam de forma objetiva e imediata sobre o sujeito. Segundo Rey (2004), a psicologia comportamental não apenas omitiu o social, mas também reificou o status natural dos processos humanos, inclusive os psíquicos. Para esse autor, a psicanálise também não rompe com o Individualismo à medida que apresenta os processos psíquicos como tendo um caráter universal e invariável. A influência da psicanálise sobre as escolas dinâmicas deu continuidade à representação da psiquê como um sistema aberto que se organiza em um sujeito individual, sendo que o social influencia, mas não constitui e organiza o psiquismo. Recentemente, porém, muitos autores, a exemplo de Guattari (1992), desenvolveram uma visão histórico-cultural da subjetividade. 
As eventuais conseqüências de uma sociedade pautada no Individualismo são: o aumento das desigualdades sociais, a indiferença diante do sofrimento alheio, a degradação dos laços sociais e do meio ambiente. Porém, para perpetuar-se e garantir sua hegemonia, criam-se mecanismos ideológicos propagados nas práticas cotidianas e difundidos principalmente pela mídia, que apontam tal cenário como natural e imutável.

Embora hegemônico nas sociedades ocidentais capitalistas contemporâneas, o individualismo foi e é alvo de críticas, existindo outras cosmovisões que visaram superá-lo, como é o caso do totalitarismo ou coletivismo, discutido a seguir.

\section{Totalitarismo ou coletivismo}

Tal cosmovisão explica as ações individuais e coletivas a partir da dominação da totalidade social sobre os indivíduos e da necessidade de reproduzila, enquanto estrutura. Ao contrário do individualismo, o que vale aqui não é o indivíduo, mas o social, que é tido como uma entidade em si, algo dado, que possui leis próprias, como as leis da natureza (Caillé, 2000; Guareschi, 2004). Caillé (2000) e Godbout (1999) denominam essa perspectiva de holismo, identificando correntes das ciências sociais onde o holismo metodológico predominou, e tudo era explicado a partir das estruturas sociais.

Nessa cosmovisão, o ser humano não é um ser autônomo, mas está sujeito ao coletivo, limitando-se a expressar os valores de sua cultura, cumprir as funções sociais determinadas ou colocar em prática as regras envolvidas na lógica da estrutura de que depende. Como as regras são exteriores, essa cosmovisão recebe críticas no que se refere à questão da restrição das liberdades (Caillé, 1998, 2000; Godbout, 1999; Guareschi, 2004).

É o "todo", o "coletivo" que predomina, não havendo espaço para o singular e o diferente, sendo as relações pautadas na massificação, no anonimato e na burocracia; são intermediadas pela formalidade e se tornam institucionalizadas (Guareschi, 2004).

Em termos do tipo de sociedade que o Totalitarismo eventualmente sustenta, tem-se a criação um Estado forte, capaz de "ordenar" a sociedade e reduzir as desigualdades. Para tanto, cria-se uma ideologia na qual destaca-se 
a imagem de um todo, de uma "união", dissimulando as desigualdades que eventualmente continuem presentes. O diferente, o que contesta, é apontado como inimigo, como ameaça, sendo lícito combatê-lo ou até matá-lo, para o bem do coletivo; ou seja, a individualidade e seus direitos inalienáveis são valores menosprezados (Guareschi, 2004). Ainda encontram-se presentes, na memória social recente, acontecimentos históricos que foram expressão do totalitarismo, tanto de direita como de esquerda, tais como o nazismo, fascismo, as ditaduras latino-americanas, o socialismo real no leste europeu, a China de Mão-Tse-Tung e a Cuba de Fidel Castro, a despeito das grandes diferenças entre eles. Para Hannah Arendt (2004):

O totalitarismo é uma forma de domínio radicalmente nova porque não se limita a destruir as capacidades políticas do homem, isolando-o em relação à vida pública, como faziam as velhas tiranias e os velhos despotismos, mas tende a destruir os próprios grupos e instituições que formam o tecido das relações privadas do homem, tornando-o assim estranho ao mundo e privando-o do seu próprio eu.

Partidos únicos, polícias truculentas, serviços "secretos" de informação nacional e forte manipulação ideológica garantem "estabilidade" social, às custas de brutal repressão. Terror, atrocidades cometidas em nome do interesse nacional - na verdade exatamente o oposto -, floresceram nos regimes totalitários, em certos períodos com perturbador apoio popular. Arendt (2004) descreve que, apesar do caráter criminoso do nazismo e das ações de Hitler, parte significativa da população alemã estava informada sobre o que acontecia com os judeus. Exemplos dramáticos desse tipo de sociedade, infelizmente, não são em pequeno número.

Em termos da ciência, especificamente das ciências sociais, pode-se entender o primado do holismo metodológico, ou seja, a explicação dos fenômenos é feita a partir do coletivo, do estrutural. Para Caillé (2000), o funcionalismo, o culturalismo, o institucionalismo e o estruturalismo são representantes dessa concepção científica. No caso da psicologia, ela pode ser identificada em algumas vertentes da psicologia soviética que, na busca de resgatar o social e construir uma teoria crítica, caiu no extremo oposto, considerando a psiquê como reflexo do social (Rey, 2004).

Práticas autoritárias podem ter lugar em âmbitos diversos, desde o espaço doméstico- familiar até o espaço público da comunidade e das relações institucionais. Interessante também é destacar que, no seio de sociedades 
individualistas - como a estadunidense - , florescem eventualmente traços totalitários, a exemplo do macarthismo, ${ }^{1}$ onde todo cidadão tinha de provar que não era comunista.

A sociedade capitalista também produz as suas próprias estruturas, eventualmente tão implacáveis que assemelham-se ao totalitarismo; ainda assim, se a presença dos impactos do capitalismo flexível sobre a subjetividade não pode ser negada, é preciso superar as visões que exacerbam o poder da máquina capitalista e apresentam o homem como um ser passivo que não oferece nenhuma resistência aos modelos homogeneizantes da subjetividade, que lhes são impostos pelo registro coletivo. O sujeito, como ser ativo e reflexivo, resiste e cria saídas para subverter os aprisionamentos (Giroux, 1983; Pelbart, 2000).

Apresentadas as cosmovisões que encontram fundamentos na modernidade ocidental, percebe-se que tanto o individualismo como o totalitarismo mostram-se incapazes de explicar a origem do vínculo social e de gerar uma sociedade justa e solidária. $\mathrm{O}$ totalitarismo não chega a questionar a gênese do vínculo social, uma vez que considera que ele pré-existe ontologicamente à ação dos sujeitos sociais; o individualismo não consegue explicar como os indivíduos, egoístas e racionais, conseguem se reunir em sociedade e cooperar (Caillé, 2000). Desta forma, buscamos descrever cosmovisões diversas que buscam superar as limitações do individualismo e do totalitarismo, discutidas a seguir.

\section{As cosmovisões emergentes: o comunitarismo solidário, o paradigma da dádiva e a cultura da partilha}

Apresentaremos nessa seção três cosmovisões emergentes - o comunitarismo solidário, o paradigma da dádiva e a cultura da partilha - e ao final, buscaremos tecer comentários que apontam seus aspectos comuns e divergentes.

Movimento iniciado nos Estados Unidos em 1951 pelo senador Joseph McCarthy (19081957), caracterizado pela perseguição a pessoas acusadas de ser simpatizantes do comunismo e de realizar atividades antinorte-americanas.

(Fonte: http://geocities.yahoo.com.br/vinicrashbr/historia/geral/marcarthismo.htm) 


\section{O Comunitarismo Solidário}

Essa cosmovisão é apresentada por Guareschi (2004), e possui no conceito de relação seu ponto central. Por relação, o autor denomina algo que vai além da mera comunicação ou troca, sendo definido como: “[...] o direcionamento intrínseco, isto é, próprio do ser, em direção a outro ser", tratando-se de uma percepção dialética, uma vez que "as coisas necessitam das outras para serem elas mesmas" (Guareschi, 2004, p. 61); no caso do ser humano, isso implica que ele necessita do outro para ser, ou seja, é uma questão ontológica. Nesse sentido, para o autor, o conceito de relação é um dos mais importantes para a psicologia social, permitindo superar o psicologismo do individualismo e o sociologismo do totalitarismo.

No Comunitarismo Solidário o ser humano é visto como relação (não como ser em relação), o outro lhe é intrínseco; não se trata de ressaltar a importância da interação, mas sim da possibilidade de constituição enquanto humano somente a partir da relação. Desta forma, embora singular, ele não pode ser sem os outros, e constitui-se a partir das relações que estabelece ao longo da vida. O autor alerta que dizer que o ser humano "é relação", é distinto de afirmar que é um "ser em relação", uma vez que alguém pode se relacionar com os outros, mas continuar fechado em si, isolado (Guareschi, 1998; 2004).

Na perspectiva da imbricação entre social e individual, cabe citar Caillé (1998, p.6), ao referir-se ao paradigma da dádiva, proposto por Marcel Mauss:

Cai ao mesmo tempo a oposição durkheimiana radical entre sociológico e psicológico, pois entre o social e o individual não há mais ruptura, mas gradação e tradução recíproca, já que os simbolismos constitutivos de um plano são passíveis de tradução nos do outro.

Uma perspectiva semelhante é encontrada em Morin (2004), quando propõe dentre os princípios de identidade, os da exclusão e da inclusão, que atuam de forma complementar. O princípio da exclusão refere-se ao fato de cada ser humano ser único, singular. Já o princípio da inclusão considera que se pode inscrever um "nós" no "eu". Desta forma, o sujeito traz em si a alteridade, tendo em si a atração para o outro, que é visto como um alter ego, 
como um outro eu mesmo, com o qual eu me relaciono. Assim, o sujeito não pode ser reduzido ao egoísmo, mas inclui também o altruísmo.

Além desse exemplo, o conceito de sujeito como relação apontado por Guareschi pode ser encontrado em outros autores, embora com abordagens mais interacionistas, como por exemplo na perspectiva da Psicologia SócioHistórica (Bock, 2001; Gonçalves, 2001), em Brandão (1998) e em Zuñiga (1994).

A Psicologia Sócio-Histórica considera os fenômenos psicológicos como resultado de um processo de constituição social do indivíduo, no qual o plano intersubjetivo, das relações, é convertido em um plano intra-subjetivo. Assim, o mundo psicológico estabelece uma relação dialética com o mundo social: “[...] falar de subjetividade é falar de objetividade [...], a compreensão do mundo interno exige a compreensão do mundo externo, pois são dois aspectos de um mesmo movimento" (Bock, 2001, p. 22).

Brandão (1998) também aponta uma visão semelhante expressa no conceito do eutro, no qual o outro não se reduz ao eu e vice-versa. Para o autor, o sujeito se constrói continuamente no encontro com os outros, ocorridos ao longo de toda a vida e não apenas nos encontros primordiais estabelecidos na infância. Somos um eu, mas irremediavelmente ligados ao outro. Esse eu é plural e múltiplo, não-linear e experimenta diversas posições identitárias, conforme esse outro cultural, discursivo, simbólico, vai lhe tingindo com sua "cor" de diferença que o desestabiliza, produzindo-o (de forma não determinística, ou imprevisível).

Numa perspectiva interacionista, Zuñiga (1994) propõe uma visão dialética entre sujeito e objeto, na qual não há primazia de um sobre o outro. Para tanto, o autor utiliza o termo pessoa, que não é sinônimo de indivíduo, mas designa um indivíduo-em-relação. A pessoa é vista como um produto da mediação social, mas que pode se transformar na medida em que transforma as estruturas que a constituíram, havendo a co-constituição mútua entre as instâncias.

Relação implica, portanto, incompletude, dinamismo. Procurar entender a sociedade e o ser humano sob esse prisma, significa realizar uma análise aberta, que deixa espaço para a mudança e a contradição, evitando abordagens ingênuas ou idealizadas de ser humano e de sociedade. 
Para designar os valores presentes nessa cosmovisão, Guareschi (2004) cita o paleontólogo francês Teilhard de Chardin e emprega o termo amoris$m o$, que se refere à relação de comunhão estabelecida entre os seres humanos e com natureza. Outro valor seria a solidariedade, sendo que o conceito de solidariedade envolve o reconhecimento da interdependência, do outro como pessoa e da responsabilidade pelo bem de todos e de cada um, possuindo uma dimensão social que exige ação, organização e articulação.

Lisboa (2003) emprega o conceito de forma semelhante, denominando-o de solidariedade consciente, indicando o reconhecimento, o respeito e o acolhimento do outro como parte intrínseca de cada indivíduo. A solidariedade consciente implica em uma co-responsabilidade que vai além do mero cumprimento de deveres, mas envolve uma postura ativa de quem acolhe o outro porque este lhe é diferente e complementar.

Desta forma, a solidariedade, no sentido aqui empregado, envolve valores como a gratuidade, a partilha, a reciprocidade, o respeito à diversidade, a comunhão e a confiança. Esses elementos, enquanto valores, compõem um quadro complexo e eventualmente contraditório, que pode implicar em formas híbridas de ação em sociedade, não existindo de forma pura na ação de criaturas supostamente "angélicas"; seu sentido, portanto, deve ser relativizado, não absolutizado. Mas a simples menção de que estão presentes e são apropriados por sujeitos sociais, já questiona o reducionismo do homo economicus.

Pautado nesses valores, o modelo de sociedade proposto pelo Comunitarismo Solidário é a comunidade, caracterizada prioritariamente por condutas pautadas pela participação, cooperação e colaboração, porém sem deixar de conter em si o contraditório, como tudo que se refere ao humano. A comunidade constitui um grupo de pessoas, não necessariamente fechado e restrito a uma localização geográfica, mas que se caracteriza por ser um local de argumentação. Embora possuindo valores e objetivos comuns e havendo a busca pelo consenso, na comunidade há espaço para discussão, para o questionamento, para a diversidade e para a mudança (Bellah, 1999).

Para Guareschi (2004), embora algumas formas de sistema ou regimes de governo eventualmente se aproximem mais dessa cosmovisão, ainda não existe um que o concretizou integralmente. Existe como uma referência e um sentido de futuro, ou como diz Santos (1996: 323), como uma utopia: “A 
utopia é a exploração de novas possibilidade e vontades humanas, por via da oposição da imaginação ao que existe, só porque existe, em nome de algo radicalmente melhor que a humanidade tem o direito de desejar e pelo que vale a pena lutar."

\section{O Paradigma da dádiva}

Costuma-se atribuir a Marcel Mauss, em sua obra "O Ensaio sobre a Dádiva”, a fundação do Paradigma da Dádiva, sendo que Caillé (2002) acrescenta George Simmel como co-fundador. Na obra citada, Mauss (2001) apresenta a descoberta empírica da universalidade de uma regra social básica entre as sociedades arcaicas que pode ser resumida na tripla obrigação de dar, receber e retribuir, colocando em circulação presentes, benefícios e bens.

Inicialmente, cabe definir o que se entende por dádiva, também denominada por dom. Para isso, toma-se Caillé (2002, p. 192), que apresenta uma definição sociológica e outra geral que são complementares:

- Definição sociológica: qualquer prestação de bens ou serviços efetuada sem garantia de retorno, tendo em vista a criação, manutenção ou regeneração do vínculo social. Na relação de dádiva, o vínculo é mais importante do que o bem.

- Definição geral: toda a ação ou prestação efetuada sem expectativa, garantia ou certeza de retorno, por esse fato, comporta uma dimensão de 'gratuidade'. O paradigma da dádiva insiste sobre a importância, positiva e normativa, sociológica, econômica, ética, política e filosófica desse tipo de ação e de prestação.

Há duas modalidades da dádiva: a dádiva agonística e a dádiva-partilha. Mauss estudou a primeira, mas apontou a existência da segunda. Caillé (2000) destaca a última, pois considera que a dádiva não deve ficar restrita a situações de cerimonialidade e de rivalidade, mas envolve inúmeras formas de partilha. Para o autor, essa perspectiva é capaz de prover a universalidade da dádiva. Ele propõe ainda que a denominação paradigma do dom ou da dádiva seja substituída por palavras como associação ou aliança.

Diante da hegemonia do neoliberalismo, propor a dádiva pode soar como algo que não merece ser considerado como alternativa credível; porém, para Caillé (2002) e Nicolas (2002), a dádiva não é exclusiva de sociedades arcaicas e não desapareceu com elas, mas ainda se faz presente nas sociedades 
complexas atuais, tanto nas relações primárias como nas secundárias, embora se concentre mais nas primeiras. Nesse sentido, o Paradigma da Dádiva tem sido resgatado e aprofundado por autores como Caillé (2000) e Godbout (1999) que, através do Movimento Antiutilitarista em Ciências Sociais MAUSS -, têm buscado identificar como o mesmo se encontra presente também na contemporaneidade. Mauss (2001) concebe a sociedade como um fenômeno relacional, incerto e aberto, que não é determinado nem pelo indivíduo nem pela totalidade social, mas constitui-se a partir da circulação contínua e paradoxal de obrigações comuns, de bens simbólicos e materiais que fabricam num movimento contínuo tanto a coletividade como os indivíduos.

A dádiva postula o homo donator que possui uma pulsão, uma tendência para a dádiva (Godbout, 1999), que não pode ser visto e entendido apenas a partir de sua individualidade. Trata-se de um ser relacional, potencialmente aberto e teleologicamente orientado para o outro, sendo que é por essa relacionalidade que ele se constitui pessoa (Silva, 2004).

Portanto, para essa cosmovisão, a totalidade social não preexiste aos indivíduos, mas ambas se geram incessantemente pelo conjunto da interrelações que as ligam. Nesse sentido, não há ruptura entre o social e o individual, mas gradação e tradução recíproca:

Ao estabelecerem relações determinadas pelas obrigações que contraem quando se aliam e ao se darem uns aos outros, submetendo-se à lei dos símbolos que criam e põem em circulação, os seres humanos produzem simultaneamente sua individualidade, sua comunidade e o conjunto social em cujo seio se exerce a sua rivalidade (Caillé, 2000, p. 67).

A relação social da dádiva é apresentada como a figura genérica de qualquer relação social, sendo que sua complexidade permite resgatar a intersubjetividade, o vínculo social e a sociabilidade. Nesse sentido, embora realizada, por vezes, por pessoas particulares, a dádiva consiste em uma atividade simbólica que se refere ao conjunto das dimensões da ação e exerce profunda repercussão em toda a sociedade, estabelecendo relações sociais que não são pautadas nas regras e valores do mercado (Caillé, 2002).

O Paradigma da Dádiva não trata os opostos como excludentes. Desta forma, integra obrigação e liberdade, interesse e desinteresse, social e indivíduo (Caillé, 2000). Ao interpretar o mundo a partir do individualismo e do totalitarismo, esses paradoxos parecem difíceis de entender. Com relação ao 
paradoxo obrigação versus liberdade, para Godbout (1999), a dádiva é vista como um prazer por aqueles que a praticam, sendo tida como inferior quando feita por obrigação. Além disso, a retribuição, embora possa estar presente, não constitui um fim, como poderia supor uma análise instrumental (individualismo), ou da adesão à norma social imposta (totalitarismo), mas tem por objetivo a manutenção do vínculo estabelecido.

Pode-se inferir, numa perspectiva sócio-psicológica, que a dádiva envolva a vivência de emoções positivas. Poderemos encontrar muitos argumentos que corroboram esses movimentos, nas relações interpessoais. Toda a relação incorpora parte desses três movimentos, pois mesmo uma interação atávica como a relação mãe-bebê, não prescinde de gratificações, ganhos narcísicos e mútuo gozo. Tanto em uma micropolítica das relações interpessoais como na macropolítica social, a reciprocidade e a dádiva poderiam compor o quadro de análise como categorias constitutivas dos laços que se criam e recriam.

O segundo paradoxo presente no Paradigma da Dádiva se refere ao interesse versus desinteresse. Caillé (2000) afirma que, embora não se possa negar a existência do interesse instrumental, a sociedade não se manteria se fosse sustentada apenas sobre o mesmo. Desta forma, a solidariedade é imprescindível e só pode emergir através da subordinação dos interesses materiais a uma regra simbólica que os transcenda, presente nas trocas efetuadas na dádiva. Para melhor distinguir o interesse presente na dádiva do interesse instrumental, o autor propõe utilizar o termo interesse para designar um interesse por si, do ter o objeto, e o termo amância para indicar o interesse pelo outro, que também caracteriza a dádiva. Um outro aspecto da dádiva é a reciprocidade, uma vez que ela se perpetua pelo dom e contra-dom, fazendo desse modo com que os atores alternem-se entre doador e recebedor, não havendo, portanto, submissão ou dominação (Nicolas, 2002).

Uma sociedade pautada no Paradigma da Dádiva permite a concretização de uma democracia direta e participativa, na qual o é assegurado ao excluído o direito de receber, mas igualmente de retribuir, de participar, de inventar, de intervir, de criar bens sociais e estabelecer vínculos duradouros, recuperando o sentido da vivência comunitária e democrática (Silva, 2004). 


\section{A Cultura da partilha}

A Cultura da Partilha é apresentada por diversos autores (Araújo, 1998; Bruni; 2002; Burckart, 2002; Lubich, 2002) vinculados ao Movimento dos Focolares, um movimento católico surgido em 1943, na Itália, tendo por fundadora Chiara Lubich. A espiritualidade proposta pelo Movimento dos Focolares baseia-se no amor recíproco e tem como objetivo promover a unidade entre os povos (Araújo, 1998).

O Movimento dos Focolares propõe a substituição da cultura competitiva, do ter, do acumular, do desperdiçar, pela Cultura da Partilha, caracterizada pelo uso moderado dos bens. Para Araújo (1998; 2002), há mais de uma forma possível para a doação: o dar contaminado pela vontade de poder, que busca a dominação do outro; o dar que busca a satisfação própria, expressão egoísta e que gera humilhação; o dar utilitarista, que visa o proveito próprio. Todas essas formas são compatíveis com Individualismo, possuindo um caráter instrumental; o dar proposto pela Cultura da Partilha refere-se ao dar no sentido cristão, que se caracteriza pela generosidade, gratuidade, abundância e desinteresse. Assim, não basta dar, se isso gera dependência de quem recebe. Na Cultura da Partilha, o dar visa lançar premissas ou criar condições para que aquele que recebe seja posto em condições de manifestar a sua livre determinação de estar em relação.

Para tal cosmovisão é preciso passar da concepção do homo economicus para a do homo donator, que se caracteriza como um ser aberto à comunhão, à relação com a divindade, com os outros e com a natureza, capaz de praticar a partilha. Trata-se de um sujeito-em-relação, que encontra sua realização quando se doa e acolhe o outro (Araújo, 2002; Bruni; 2002; Lubich, 2002).

Nesse sentido, as condutas propostas pela Cultura da Partilha são caracterizadas pela comunhão, partilha de bens materiais e espirituais, abertura, confiança, gratuidade e reciprocidade (Araújo, 2002).

Para Burckart (2002), a Cultura da Partilha apresenta uma visão antropológica que supera o Individualismo a partir de um estilo de vida comunitário, sendo que indivíduo e sociedade são vistos como distintos, mas inseparáveis, estabelecendo um relacionamento harmonioso. Assim, a comunidade constitui o local apropriado para a vivência da Cultura da Partilha (Bruni, 2002; Araújo, 1998; Burckart, 2002). 
Numa análise mais crítica, o sentido atribuído à comunidade, contudo, parece não corresponder àquele presente no Comunitarismo Solidário, mas quer designar um grupo de pessoas caracterizado por relacionamentos próximos e afetuosos. Embora sejam citadas a questão da pluralidade e a diversidade, a impressão que se tem é de que trata-se de um grupo necessariamente homogêneo, no qual o conflito deve ser evitado.

Algumas empresas que supostamente alinham-se ao paradigma, sendo seus gestores integrantes do movimento dos Focolares, praticam a tradicional divisão e organização capitalista do trabalho, procurando contudo humanizar tais relações (Carvalho, 2005).

Apresentadas três cosmovisões relacionais, Comunitarismo Solidário, Paradigma da Dádiva e Cultura da Partilha, passamos agora a comentar suas semelhanças e diferenças.

\section{Semelhanças e diferenças entre as cosmovisões relacionais}

Para realizar a comparação entre as três cosmovisões apresentadas, apresentaremos inicialmente o quadro a seguir, para depois tecer alguns comentários. Embora uma cosmovisão seja composta por diversos elementos, optamos por destacar os citados por Guareschi (2004) - concepção do ser humano, valores, tipo de sociedade e condutas - por considerarmos que os mesmos são centrais para caracterizar cada cosmovisão: 
Quadro 1: Comparação entre as cosmovisões relacionais

\begin{tabular}{|l|l|l|l|}
\hline $\begin{array}{l}\text { Elementos da } \\
\text { cosmovisão }\end{array}$ & $\begin{array}{l}\text { Comunitarismo } \\
\text { Solidário }\end{array}$ & $\begin{array}{l}\text { Paradigma } \\
\text { da Dádiva }\end{array}$ & $\begin{array}{l}\text { Cultura } \\
\text { da Partilha }\end{array}$ \\
\hline $\begin{array}{l}\text { Concepção de } \\
\text { ser humano }\end{array}$ & Pessoa = Relação & $\begin{array}{l}\text { Sujeito = relação } \\
\text { Homo donator }\end{array}$ & $\begin{array}{l}\text { Sujeito em relação } \\
\text { Homo donator }\end{array}$ \\
\hline Valores & $\begin{array}{l}\text { Solidarismo, } \\
\text { Amorismo, } \\
\text { Singularidade }\end{array}$ & $\begin{array}{l}\text { Solidarismo } \\
\text { Amância } \\
\text { Confiança }\end{array}$ & $\begin{array}{l}\text { Solidarismo } \\
\text { Amor recíproco } \\
\text { Confiança }\end{array}$ \\
\hline $\begin{array}{l}\text { Tipo de socie- } \\
\text { dade }\end{array}$ & Comunidade & Não especificada & Comunidade \\
\hline Condutas & Solidariedade & $\begin{array}{l}\text { Solidariedade } \\
\text { Cooperação } \\
\text { Reciprocidade } \\
\text { Gratuidade }\end{array}$ & $\begin{array}{l}\text { Solidariedade } \\
\text { Cooperação } \\
\text { Reciprocidade } \\
\text { Gratuidade } \\
\text { Partilha }\end{array}$ \\
\hline
\end{tabular}

Fonte: Guareschi, 2004.

Conforme já assinalado, as três cosmovisões têm como uma das semelhanças o fato de realizarem uma crítica ao individualismo e ao totalitarismo e apresentarem-se como uma alternativa, que rompe com o dualismo indivíduo versus sociedade.

Outro aspecto comum é a ênfase no conceito da relação, motivo pelo qual as denominamos de cosmovisões relacionais. Mas fazem-se necessários alguns esclarecimentos. No Comunitarismo Solidário e no Paradigma da Dádiva, o conceito de relação parece ser empregado em sentido semelhante, para designar o direcionamento intrínseco em direção ao outro ser. Daí decorre o fato de apresentarem o ser humano como sujeito = relação, o que indica que consideram que o sujeito se constitui a partir e pelas relações que estabelece com os demais. Não há uma essência imutável, mas uma contínua construção, na medida em que a cada relação "deixa" um pouco de si e "leva" um pouco do outro. Além disso, no caso do Paradigma da Dádiva, a denominação de cosmovisão relacional refere-se também ao esforço de buscar explicar a origem do vínculo social.

Já na Cultura da Partilha o ser humano é definido como sujeito-emrelação. Embora proponha que o mesmo se realize somente quando se doa 
aos demais, essa afirmação não implica em dizer que o outro lhe é intrínseco e que o sujeito é constituído a partir das relações estabelecidas com os demais. Ou seja, o termo relação parece ser empregado no sentido tradicional indicando troca, comunicação, sociabilidade. A ênfase parece estar sobre a valorização das relações primárias, sempre apontadas sob uma ótica positiva. Das três cosmovisões, parece-nos a mais idealizada, faltando-lhe o elemento de complexificação, a consciência do caráter contraditório da experiência humana. Recentes estudos empíricos (Carvalho, 2005) apontam para o caráter contraditório entre o discurso e as práticas dos empresários Focolares.

A divergência quanto ao conceito de relação tem implicações sobre a questão da mudança social. Ao se afirmar que sujeito = relação, há uma ênfase maior na transformação social e na ação dos sujeitos nesse processo, uma vez que no contínuo indivíduo-sociedade há uma ontológica implicação mútua. Conforme aponta Zuñiga (1994), o sujeito é visto como um produto da mediação social, mas que pode se transformar na medida em que transforma as estruturas que o constituíram. Já na perspectiva da Cultura da Partilha, essa transformação parece ser baseada em uma mudança interior do sujeito, que repercute nas relações primárias, e que refletiria na sociedade, não salientando, entretanto, a questão das mudanças na estrutura social. Ao contrário, a manutenção do equilíbrio é o objetivo das condutas.

Pode-se dizer que nas cosmovisões relacionais, há tanto um resgate do sujeito, à medida que sua singularidade é afirmada, bem como um resgate do outro, considerando-o como um alter ego, sendo que é na relação que o sujeito encontra sua realização. O outro deixa de ser o empecilho, o rival, ou objeto de satisfação própria (individualismo); mas também não é o Todo, aquele ao qual devo me submeter, e do qual devo ser o mero reflexo (totalitarismo).

$\mathrm{Na}$ Cultura da Partilha está presente a dádiva, não só no dom de bens materiais, mas do próprio ser. A dádiva, no caso denominada de partilha, também aqui é realizada na liberdade, gratuitamente e tal postura acaba gerando um comportamento recíproco por parte do outro. É interessante notar que tanto Araújo (2002) como Godbout (1999) utilizam o termo homo donator para designar o sujeito proposto pelas cosmovisões que representam.

Com relação aos valores propostos pelas cosmovisões relacionais, destacamos as distintas designações - amorismo, amância e amor recíproco - 
utilizados no sentido de designar o interesse pelo outro, a relação de comunhão estabelecida com os demais.

Conforme já destacado, essas cosmovisões incluem a preocupação em resgatar os vínculos sociais duradouros, enfatizar as relações primárias pautadas na confiança, na solidariedade, na comunhão. De certa forma, diante da fluidez dos vínculos da atualidade, visam resgatar valores de "longo prazo": num mundo globalizado, padronizado e massificado, resgatam a comunidade; num mundo de vínculos frágeis, resgatam o vínculo duradouro; num mundo de competição predatória, resgatam a cooperação.

Ao propor o modelo de sociedade como comunidade, as cosmovisões relacionais enfatizam a relação próxima, onde cada um é chamado pelo nome e reconhecido em sua singularidade (Guareschi, 2004). Porém, conforme assinalado, o termo comunidade parece ter uma conotação mais tradicional na visão da Cultura da Partilha, indicando um grupo de pessoas que partilham valores e objetivos, e na qual deve haver ausência de conflito e contradição; enquanto no Comunitarismo Solidário, deixa-se claro que comunidade não implica em homogeneidade, mas no espaço no qual o consenso é alcançado através do argumentação, da ação comunicativa, havendo lugar para divergências e para a mudança. Com relação ao Paradigma da Dádiva, não encontramos nas referências consultadas uma definição mais explícita sobre o modelo de sociedade proposto. Apenas no texto de Silva (2004), destaca-se que ações calcadas no Paradigma da Dádiva podem permitir a efetivação de uma vida comunitária.

Como dito no inicio desse texto, uma cosmovisão traduz-se em práticas. Embora ainda não com a mesma força das cosmovisões vigentes - individualismo e totalitarismo - pode-se identificar ações que constituem uma tentativa de concretização do que denominamos cosmovisões relacionais.

No caso do Paradigma da Dádiva, a doação de sangue, as doações humanitárias, os grupos de ajuda mútua, como os Alcoólicos Anônimos, são citados por Lechat (2003) como exemplos dessa cosmovisão nas sociedades contemporâneas.

Embora as alternativas ligadas as cosmovisões relacionais estejam eventualmente presentes em áreas diversas (ecologia, educação, saúde, tecnologia, política etc), traduzidas em ações como software livre, Orçamento Participa- 
tivo, Movimento Fórum Social Mundial, nos limitaremos a enfocar aqui aquelas referentes à esfera da produção econômica, que constituem o foco de nossas pesquisas atuais. De fato, esse campo tem se destacado como um terreno fecundo para a emergência de diversas propostas alternativas que visam gerar mudanças profundas, na tentativa de suplantar o capitalismo e que vão ao encontro da vivência e proposição das cosmovisões relacionais. Essa "outra economia" baseia-se na afirmação de Temple (apud Godbout, 1999) que considera que produzir para partilhar é diferente de produzir para acumular.

A Economia de Comunhão, por exemplo, constitui uma proposta pautada na Cultura da Partilha, na qual as empresas devem repartir seus lucros de modo a destinar parte dos mesmos aos pobres. Além disso, o empresário deve manter uma conduta ética com concorrentes, clientes, fornecedores, empregados e com o Estado. Há ainda uma cooperação entre as empresas participantes do projeto, envolvendo tanto auxílios financeiros quanto o compartilhamento de tecnologias e patentes (Ferrucci, 1998; Lubich; 2002). Sabe-se, entretanto, que eventualmente o modelo do "bom patrão", ao qual se deve adesão incondicional, pode levar a distorções significativas nas organizações que almejam o modelo da Comunhão (Carvalho, 2005).

Outro exemplo a ser citado é a Economia Solidária, que consiste em diversas modalidades de organização econômica (associações, cooperativas, empresas de autogestão, mutirões, mutualidades) constituídas a partir da livre associação dos trabalhadores, geridas a partir dos princípios de autogestão, cooperação, solidariedade e viabilidade econômica. Há um rompimento com a lógica capitalista, através da minimização da divisão entre trabalhadores e meios de produção, trabalho e capital, produção e apropriação. Os conceitos de desenvolvimento e eficiência na Economia Solidária não se baseiam apenas em aspectos econômicos, mas destacam as questões humanas e sociais, o respeito ao meio ambiente, tendo como foco não a acumulação, mas o atendimento das necessidades elementares e da qualidade de vida para todos, valorizando o compromisso com a comunidade na qual se insere. A partir de pesquisas recentes, foi cunhado o termo "empreendimento econômico solidário" (EES) para definir, genericamente, as organizações que buscam atingir tais metas (Arruda, 2003; Gaiger, 2004). São citados exemplos como os sistemas locais de troca, o cooperativismo aderente aos sete princípios dos fun- 
dadores, os sistemas de microcrédito, os grupos associativos em nível comunitário, dentre outros (Andion, 2001; Arruda, 2003; Mance, 2004).

A diversidade de projetos indica a criatividade e o respeito à pluralidade na busca de soluções eficazes para as desigualdades sociais. Embora adotando práticas distintas, tais propostas têm como pontos em comum o resgate de valores salientados nas cosmovisões relacionais como a cooperação, participação, partilha, reciprocidade, ética e solidariedade. Além disso, trata-se de projetos construídos na e pela comunidade, que visam substituir o modelo de desenvolvimento pautado apenas no aspecto econômico, por um desenvolvimento social e sustentável (Coraggio, 2001; Arruda; 2003; Cattani, 2003; Gaiger, 2004).

Segundo o Atlas da Economia Solidária no Brasil, fruto do mapeamento nacional realizado pela Senaes-MTE, ${ }^{2}$ a Economia Solidária é compreendida como o conjunto de atividades econômicas de produção, distribuição, consumo, poupança e crédito, organizadas e realizadas solidariamente por trabalhadores/as sob a forma coletiva e autogestionária. Foram mapeados 14.954 empreendimentos econômicos solidários do Sul ao Norte do país, envolvendo mais de 1 milhão de pessoas nessas atividades. Aqui tem-se um exemplo de relações econômicas e práticas sociais pautadas pelos valores das cosmovisões relacionais.

Há ainda que se destacar que a superação do individualismo e do totalitarismo e a concretização das cosmovisões relacionais não se realiza sem resistência, sem a presença de muitas contradições. Nesse sentido, Santos (2002), Cattani (2003) e Spink (2004) alertam para a questão de que se, por um lado, devam-se evidenciar as qualidades emancipatórias das propostas alternativas, por outro, é necessário lançar sobre elas um olhar crítico, uma vez que constituem um conjunto diverso e controverso. Por um lado, existem aquelas que são portadoras de verdadeiras mudanças; por outro lado, outras acabam se reduzindo, enquanto práticas sociais, a projetos inconsistentes, que reproduzem e reforçam as cosmovisões a serem eventualmente superadas. Isso, na perspectiva da necessidade de superação - o que por si só já será controverso - mas que é aquela que assumimos nesse texto.

2 Secretaria Nacional de Economia Solidária, ligada ao Ministério do Trabalho e Emprego. Home-page: http://www.mte.gov.br/empregador/economiasolidaria/conteudo/atlas.asp. 


\section{Cosmovisões em movimento}

As discussões e concepções propostas pelo que denominamos de cosmovisões relacionais podem ser encontradas em diversos autores, conforme apontado no decorrer desse trabalho. Embora alguns de seus conceitos estejam presentes - mesmo que parcialmente -, em autores clássicos, como Marx e Mauss, parece-nos que recentemente tais conceitos têm sido retomados, aprofundados, como é o caso do Paradigma da Dádiva e outros, originando novas perspectivas, como o Comunitarismo Solidário e Cultura da Partilha. Tratam-se, portanto, de teorias em construção, embora fruto de reflexões e práticas que há tempos, de forma não-linear, produzem-se e inquietam teóricos, ativistas e cidadãos.

Com as questões aqui discutidas, não queremos apenas contribuir para uma discussão acadêmica, uma vez que, conforme apontado, uma cosmovisão se traduz em práticas; buscamos também realizar uma hermenêutica das emergências, como propõe Santos (2002). O tempo em que vivemos é pleno de alternativas, proposições e ações, a despeito da ideologia do "pensamento único" que ainda insiste em procurar legitimar-se nas sociedades ocidentais contemporâneas.

Por fim, salientamos que as considerações aqui expostas são preliminares, não pretendendo esgotar o assunto. A continuidade do aprofundamento teórico, através de novas leituras, bem como a discussão com outros pesquisadores, contribuirão para a elaboração do tema. Desejamos seguir esse caminho no nosso trabalho intelectual; consideramos que o desejo e a atividade são dispositivos fundamentais de transformação social, podendo constituir a afirmação da nossa capacidade de interferir no contexto, da nossa dimensão instituínte. E também da nossa capacidade de criar contra-saberes, sempre que os nossos saberes se mostrarem condutores de dogmatismos estéreis.

\section{Referências}

ANDION, Carolina. As particularidades da gestão em organizações da Economia Solidária. Campinas: XXV Enanpad, 2001.

ARAÚJO, Vera. Economia de Comunhão e comportamentos sociais. In: COSTA, Rui et al. Economia de Comunhão. Vargem Grande Paulista: Cidade Nova, 2. ed., 1998. p. $9-20$. 
. Que pessoas e que sociedade para a Economia de Comunhão? In: BRUNI, Luigi (Org). Economia de Comunhão: uma cultura econômica de várias dimensões. Vargem Grande Paulista: Cidade Nova, 2002. p. 21-30.

ARRUDA, Marcos. Socioeconomia solidária. In. CATTANI, Antonio D. (Org.). A outra economia. Porto Alegre: Veraz Editores, 2003. p. 232-241.

BARCELOS, Tânia Maia. Subjetividade: inquietações contemporâneas. Educação e filosofia, v. 32, n 16, p. 149-159, 2002.

BAUMAN, Zygmunt. Modernidade líquida. Rio de Janeiro: Jorge Zahar, 2001.

- Amor líquido: sobre a fragilidade dos laços humanos. Rio de Janeiro: Jorge Zahar, 2004.

BELLAH, Robert. Comunitarismo ou liberalismo? Brasil e Estados Unidos em debate. In: SOUZA, Jessé (Org.). O malandro e o protestante: a tese weberiana e a singularidade cultural brasileira. Brasília: Editora Universidade de Brasília, 1999. p. 295315.

BOCK, Ana Mercês Bahia. A Psicologia sócio-histórica: uma perspectiva crítica em psicologia. In. BOCK, Ana Mercês Bahia et al. (Orgs.). Psicologia sócio-histórica: uma perspectiva crítica em psicologia. São Paulo: Cortez, 2001. p. 15-36.

BRANDÃO, Carlos Rodrigues. Eu, outro, eutro. In. BRANDÃO, Carlos R. et al. (Orgs.). Criatividade e novas metodologias. São Paulo: Petrópolis, 1998. p. 103-117.

BRUNI, Luigi. Rumo a uma racionalidade econômica capaz de comunhão. In: BRUNI, Luigi (Org.). Economia de Comunhão: uma cultura econômica de várias dimensões. Vargem Grande Paulista: Cidade Nova, 2002. p. 41-66.

CARVALHO Neto, Antônio. Relações de trabalho e negociação coletiva na virada do milênio. Petrópolis: Vozes; São Paulo: Unitrabalho, 2001.

BURCKART, Hans. Desenvolvimento sustentável e gerenciamento empresarial: elementos para um novo paradigma de gestão. In: BRUNI, Luigi (Org.). Economia de Comunhão: uma cultura econômica de várias dimensões. Vargem Grande Paulista: Cidade Nova, 2002. p. 67-87.

CAILLÉ, Alain. Antropologia do Dom: terceiro paradigma. Petrópolis: Vozes, 2002.

CAILLÉ, Alain. Nem Holismo nem Individualismo metodológicos: Marcel Mauss e o paradigma da dádiva. Revista Brasileira de Ciências Sociais. São Paulo, v. 13, n. 38, 1998.

CARVALHO, Maria Luisa. A emergência de cosmovisões relacionais. Ensaio temático para exame de qualificação do Programa de Pós-Graduação em Psicologia da PUCRS, 2005 (mimeo).

CATTANI, Antonio David. A outra economia: os conceitos essenciais. In. CATTANI, Antonio David (Org). A outra economia. Porto Alegre: Veraz Editores, 2003. p. 914. 
CORAGGIO, Jose Luis. Problematizando la economía solidaria y la globalización alternativa. Presentación en el II Encuentro Internacional sobre Globalización de la Solidaridad, 2001. Disponível em: http://www.fronesis.org/jlc/QuebecJLC.doc. Acesso em: 10 mar. 2003.

FERRUCCI, Alberto. Considerações sobre a Economia de Comunhão. In: COSTA, Rui et al. (Orgs.). Economia de Comunhão. Vargem Grande Paulista: Cidade Nova, $2^{\mathrm{a}}$ ed., 1998. p. 69-92.

GAIGER, Luiz Inácio. Empreendimentos econômicos solidários. In: CATTANI, Antonio David. (Org). A outra economia. Porto Alegre: Veraz Editores, 2003. p. 135142.

- Sentidos e experiências da economia solidária no Brasil. São Paulo: Unitrabalho, 2004.

GIROUX, Henry. Pedagogia radical. São Paulo: Cortez, 1983.

GODBOUT, Jacques. O espírito da dádiva. Rio de Janeiro: FGV, 1999.

GONÇALVES, Maria. A Psicologia como ciência do sujeito e da subjetividade: a historicidade como noção básica. In: BOCK, Ana Mercês Bahia et al. (Orgs.). Psicologia sócio-histórica: uma perspectiva crítica em psicologia. São Paulo: Cortez, 2001. p. 37-52.

GUARESCHI, Pedrinho. Relações comunitárias - relações de dominação. In. CAMPOS, Regina. Psicologia comunitária: da solidariedade à autonomia. Petrópolis: Vozes, 1998. p. 81-99.

- O novo rosto do amor. In. MADALOZZO, Avelino. Da inteligência ao coração e à ação. Porto Alegre: Edipucrs, 1997. p. 9-16.

Alteridade e relação: uma perspectiva crítica. In: ARRUDA, Angela. Representando a alteridade. Petrópolis: Vozes, 1998. p. 149-162.

. Psicologia social crítica: como prática de libertação. Porto Alegre: Edipucrs, 2004.

GUATTARI, Felix. Caosmose: um novo paradigma estético. Rio de Janeiro: Editora 34, 1992.

KHEL, Maria Rita. Função fraterna. Rio de Janeiro: Imago, 2000.

KHUN, Thomas. A estrutura das revoluções cientificas. São Paulo: Perspectiva, 1987.

KLEY, Roland. Justiça. In: ENDERLE, Georges et al. (Orgs.). Dicionário de ética econômica. São Leopoldo: Unisinos, 1997. p. 354-358.

LECHAT, Noële. Economia da Dádiva. In: CATTANI, Antonio David. (Org.). A outra economia. Porto Alegre: Veraz Editores, 2003. p. 84-87.

LISBOA, Armando Mello. Solidariedade. In: CATTANI, Antonio David (Org.). A outra economia. Porto Alegre: Veraz Editores, 2003. p. 242-249. 
LUBICH, Chiara. A experiência Economia de Comunhão: da espiritualidade da unidade, uma proposta de agir econômico. In: BRUNI, Luigi (Org.). Economia de Comunhão: uma cultura econômica de várias dimensões. Vargem Grande Paulista: Cidade Nova, 2002. p. 13-19.

MANCE, Euclides. A colaboração solidária: compreendendo, transformando e conectando o que já existe. Artigo internet, 2004. Disponível em:

<www.milenio.com.br/mance/colaboracao.htm>. Acesso: 20 dez. 2005.

PELBART, Peter. A vertigem por um fio: políticas da subjetividade contemporânea. São Paulo: Iluminuras, 2000.

PIES, Ingo. Liberalismo. In: ENDERLE, Georges et al. (Orgs.). Dicionário de ética econômica. São Leopoldo: Unisinos, 1997. p. 359-361.

MAUSS, Marcel. Ensaio sobre a dádiva. Lisboa: Edições 70, 2001.

MORIN, Edgar. A cabeça bem-feita: repensar a reforma, reformar o pensamento. $9^{\mathrm{a}}$ ed. Rio de Janeiro: Bertrand Brasil, 2004.

NICOLAS, Guy. O dom ritual, face velada da modernidade. In: MARTINS, Paulo Henrique (Org.). A dádiva entre os modernos. Petrópolis: Vozes, 2002. p. 33-62.

REY, Fernando Gonzalez. O social na psicologia e a psicologia social. Petrópolis: Vozes, 2004.

SANTOS, Boaventura de Sousa. Globalização: fatalidade ou utopia? Porto: Afrontamento, 2001.

Produzir para viver: os caminhos da produção não capitalista. Rio de Janeiro: Civilização Brasileira, 2002.

SENNET, Richard. A corrosão do caráter. Rio de Janeiro: Record, 1999.

SILVA, Drance. Dádiva, cidadania e solidariedade. Artigo internet. Disponível em: http://www.cenap.org.br/_novosite/1 cnprodas/textos/dadiva.htm>. Acesso em: 10 ago. 2004.

SINGER, Paul. Introdução à economia solidária. São Paulo: Fundação Perseu Abramo, 2002.

VERONESE, Marilia Veríssimo. A psicologia na transição paradigmática: um estudo sobre o trabalho na economia solidária. Tese de doutorado em Psicologia, PUC-RS, 2004.

WIELAND, Josef. Individualismo. In: ENDERLE, Georges et al. (Orgs.). Dicionário de ética econômica. São Leopoldo: Unisinos. p. 342-344.

ZUÑIGA, Ricardo. Teoria y método: actores y sujetos. Suplementos Anthropos, Barcelona, n. 44, jun. 1994, p. 5-9.

Recebido em 14 de agosto de 2006 e aprovado em 28 de novembro de 2006 